
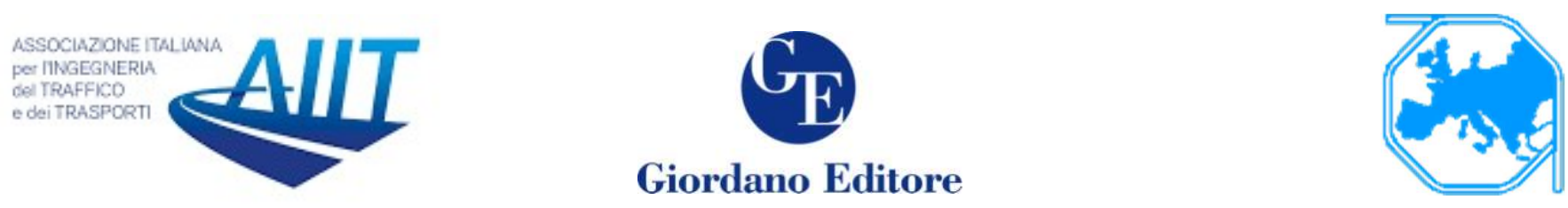

\title{
Assessment of traffic safety at median openings using surrogate safety measures: a case study in India
}

\author{
Malaya Mohanty ${ }^{1}$, Partha Pratim Dey ${ }^{2}$, and Bhagyashree Panda ${ }^{3}$ \\ ${ }^{1}$ Assistant Professor, KIIT University, Bhubaneswar, India, malaya.mohantyfce@kiit.ac.in \\ ${ }^{2}$ Assistant Professor, IIT Bhubaneswar,India,ppdey@iitbbs.ac.in \\ ${ }^{3}$ Assistant Professor, KIIT University, Bhubaneswar, India, bhagyashree.panda@kiit.ac.in
}

\begin{abstract}
Traffic safety is an integral part of transportation engineering. In developing countries, its importance is even more. Additionally, at uncontrolled median openings, the severity of road crashes increase many fold. Conventionally, road crash data were used to analyse safety. However, in developing countries, the accuracy of this data is highly questionable. Therefore, in this study, a new technique in addition to post encroachment time (PET), which is a surrogate safety measure is used to predict the severity of probable road crashes at median openings. After the extraction of PET values from field data, they have been compared with the minimum braking times obtained from calculation of minimum stopping sight distance. The comparison shows that while the number of road crashes may be less at lower traffic volume levels, however the severity of those crashes is much higher as compared to the road crashes occurring at high traffic volumes.
\end{abstract}

Keywords: Traffic Safety, PET, Median opening, Stopping sight distance

\section{Introduction}

Road safety is a major concern in the developing countries because of its influence on the worldwide economy and people's welfare. India is the second largest populated country. According to the 'World Population Prospects: The 2017 Revision' published by UN department of economic and social affairs, by 2024 India might surpass China to be the most populous country in the World. This increase in population has led to higher traffic safety risk as the present road infrastructure is not able to cope up with higher traffic demands (Killi and Vedagiri, 2014). In 2017, around 465,000 road accidents have been reported in India in which 148,000 people have lost their lives (MORTH, 2017). This leads to a severity rate of 32 persons killed per 100 road accidents. Every hour, road accidents in India takes lives of around 17 people (MORTH, 2017).

Among various traffic facilities, unsignalized median openings pose a high threat for possibility of collisions. The U-turning movements at median openings are very complex and risky due to heavy traffic volumes along with the higher speed of approaching through vehicles. Moreover, the U-turning vehicles have to make a complete 180 degree maneuver to merge with the approaching vehicle traffic stream (Aldian and 
Taylor, 2001; Mohanty and Dey, 2018). Mainly in developing countries like India, the drivers do not follow rules of priority and attempt to enter unsignalized median openings with a risk of collision (Mohapatra et al., 2016). Therefore, these median openings pose a high risk to road users. Traditionally, safety analysis was being conducted based on available crash reports (Songchitruksa and Zha, 2014, Killi and Vedagiri, 2014; Caliendo and Guida, 2012). However, due to unavailability of accurate data accompanied by nonreporting of numerous road accidents, the analysis of crash reports no more serves to prevent the road crashes. Studies have shown that microscopic simulation is able to predict the risks within a traffic flow to a certain extent (Vedagiri and Pragna, 2013). However, according to Darzentas et al. (1980) it is challenging to assess accidents and find its cause because of the varying paths in the real and simulated cases. Therefore, there is a need to develop road safety indicators that could allow a safety analysis without having to wait for a crash to occur (Caliendo and Guida, 2012). Various surrogate traffic measures have been used in the past by researchers to assess the traffic safety. Some of the usually used traffic safety surrogate measures are gap acceptance (GT), deceleration time (DT), time to collision (TTC), and post encroachment time (PET) (Archer, 2005). However, one of the most commonly used and reliable method to analyze traffic safety is PET (Gettman and Head, 2003; Killi and Vedagiri, 2014). PET is a surrogate safety measure which is used to identify cases in which two road-users pass over a common spatial point or area with a temporal difference (Archer, 2005; Killi and Vedagiri, 2014). PET is the time difference between the exit of first vehicle from the conflict spot and arrival/entry of the second vehicle at the conflict spot. A smaller PET value implies a greater probability of collision (Killi and Vedagiri, 2014). Many researchers in the past have also attempted to calculate the threshold PET values for different traffic facilities. According to Pulugurtha et al. (2019), several PET values ranging from 1 to $6.5 \mathrm{~s}$ have been historically used. AASHTO uses $1 \mathrm{~s}$ as threshold PET value for unexpected driving situation or hazardous situation (Pulugurtha et al., 2019).

Most of the aforementioned researchers have conducted studies on PET values and have also calculated the threshold PET values. However, PET value has not been calculated at median openings. The traffic safety at median openings is an area that has not been researched much in the past literatures. Furthermore, in developing countries like India, where mixed traffic condition is prevalent with no lane discipline, a single threshold PET value for various road traffic conditions, different traffic volume levels and speeds is practically unreasonable. Therefore, using the technique of stopping sight distance as per Indian Road Congress (IRC)'s IRC 66-1976 code, a new concept has been proposed to assess the road safety at median openings in a much better and scientific way. In the present study, the use of Indian road guidelines and PET, a surrogate safety measure has been used in combination to predict the severity of probable road crashes (if occurs) at different traffic volumes within the median opening area.

\section{Site Selection, Data Collection \& Methodology}

\subsection{Site Selection and Data Collection}

In order to assess traffic safety at uncontrolled median openings, 7 sites have been selected for data collection. All the selected median openings are on 6-lane divided urban roads. In order to have a better results in the study, the sites have been selected at different cities of India having same demographic characteristics. Bhubaneswar has been declared as a smart city in India where the primary study has been conducted. Sites from 5 smart 
cities have been used in the present study for a result that can be adopted in cities with similar traffic characteristics. The test sections were selected in such a way that the traffic flows at these sites are not influenced by any vertical or horizontal curve, presence of any intersection on upstream or downstream direction, parked vehicles, bus stop, pedestrian movements, or any kind of side friction. All the road sections had a raised curb on either side of the road. Video recording technique has been used to collect data from the field. 2 cameras $\left(\mathrm{C}_{1}\right.$ and $\left.\mathrm{C}_{2}\right)$, as shown in Figure 1 was placed for data collection. The traffic data was recorded from the centre of the median opening to $3.3 \mathrm{~m}$ on the downstream of the end of median opening. This distance is reported to be the maximum distance on the downstream of the end of median opening where the merging maneuver of U-turning vehicle ends and they start moving parallel to the direction of approaching through vehicle stream (Mohapatra et al., 2015). The data have been collected on typical weekdays ranging across different traffic volume levels. Following the collection of data, the videos are transferred to a PC where the required traffic data is extracted using a video analyzing software named 'Kinovea'.

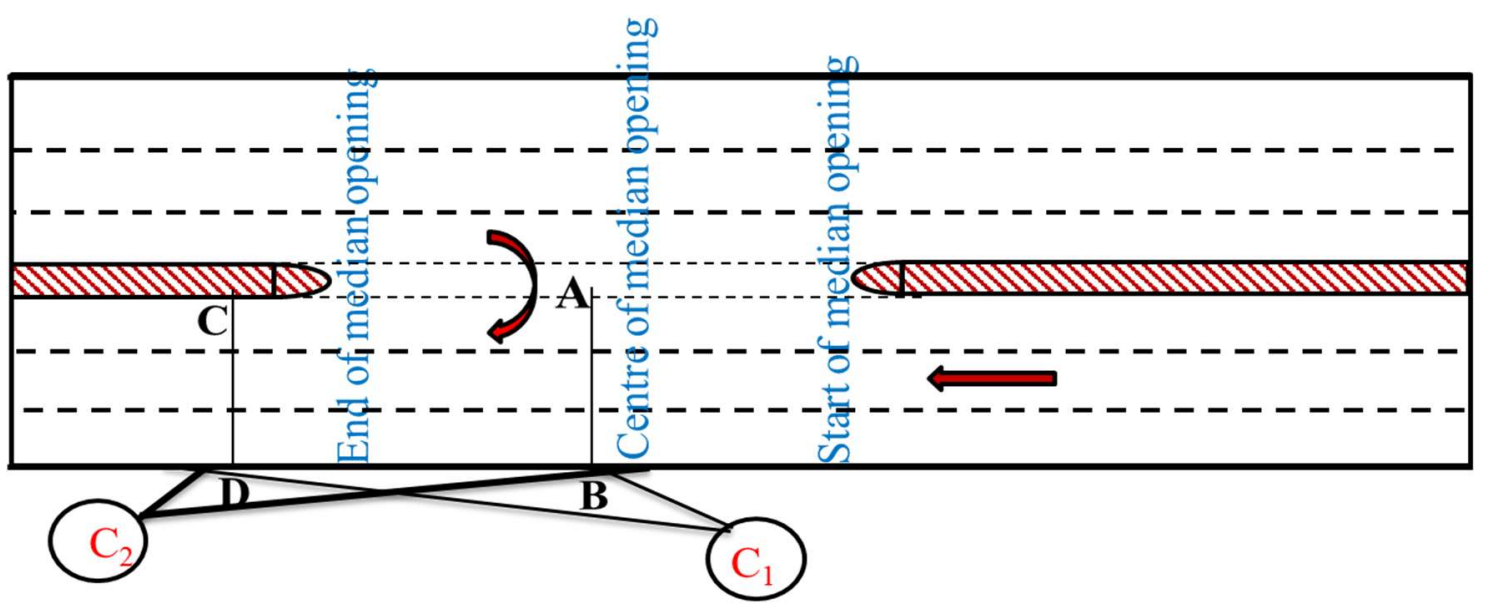

Figure 1 Camera set up for data collection

The following data has been extracted from the collected videos.

(i) The speed of each vehicle while crossing the median opening (i.e. from start to end of median opening) at different traffic volume levels.

(ii) The PET values for vehicles at different traffic volumes.

The geometrical details of the seven data collection sites used for this study are shown in Table 1.

Table 1 Geometric details of different data collection sites

\begin{tabular}{lccccccc}
\hline Section no. & $\mathbf{1}$ & $\mathbf{2}$ & $\mathbf{3}$ & $\mathbf{4}$ & $\mathbf{5}$ & $\mathbf{6}$ & $\mathbf{7}$ \\
\hline Width of median opening, $\mathbf{m}$ & 20 & 17.7 & 19.8 & 20.1 & 19.8 & 19.5 & 20.2 \\
\hline Width of raised median, $\mathbf{m}$ & 1.3 & 1.0 & 1.2 & 1.0 & 1.1 & 1.3 & 1.2 \\
\hline $\begin{array}{l}\text { Width of carriageway in one } \\
\text { direction, } \mathbf{m}\end{array}$ & 9.6 & 9.6 & 9.8 & 9.9 & 9.6 & 10 & 9.7 \\
\hline
\end{tabular}


It was observed that the average approaching traffic volumes ranged from 1200 $\mathrm{vph}$ to $6000 \mathrm{vph}$ and the U-turning traffic volumes ranged from $100 \mathrm{vph}$ to as high as $1600 \mathrm{vph}$ in all the 7 median opening sections. Located in a developing country, the traffic is heterogeneous with around $55 \%$ of vehicles being two-wheelers. While out of the rest $45 \%, 30-35 \%$ consisted of cars, LCVs and SUVs, around 8-13\% of traffic consisted of three-wheelers. Only about $1-2 \%$ of heavy vehicles were found to be plying on these roads.

\subsection{Methodology}

A simple yet efficient flow of technique ensures an accurate analysis. Figure 2 below shows the flow chart that has been employed for this study.

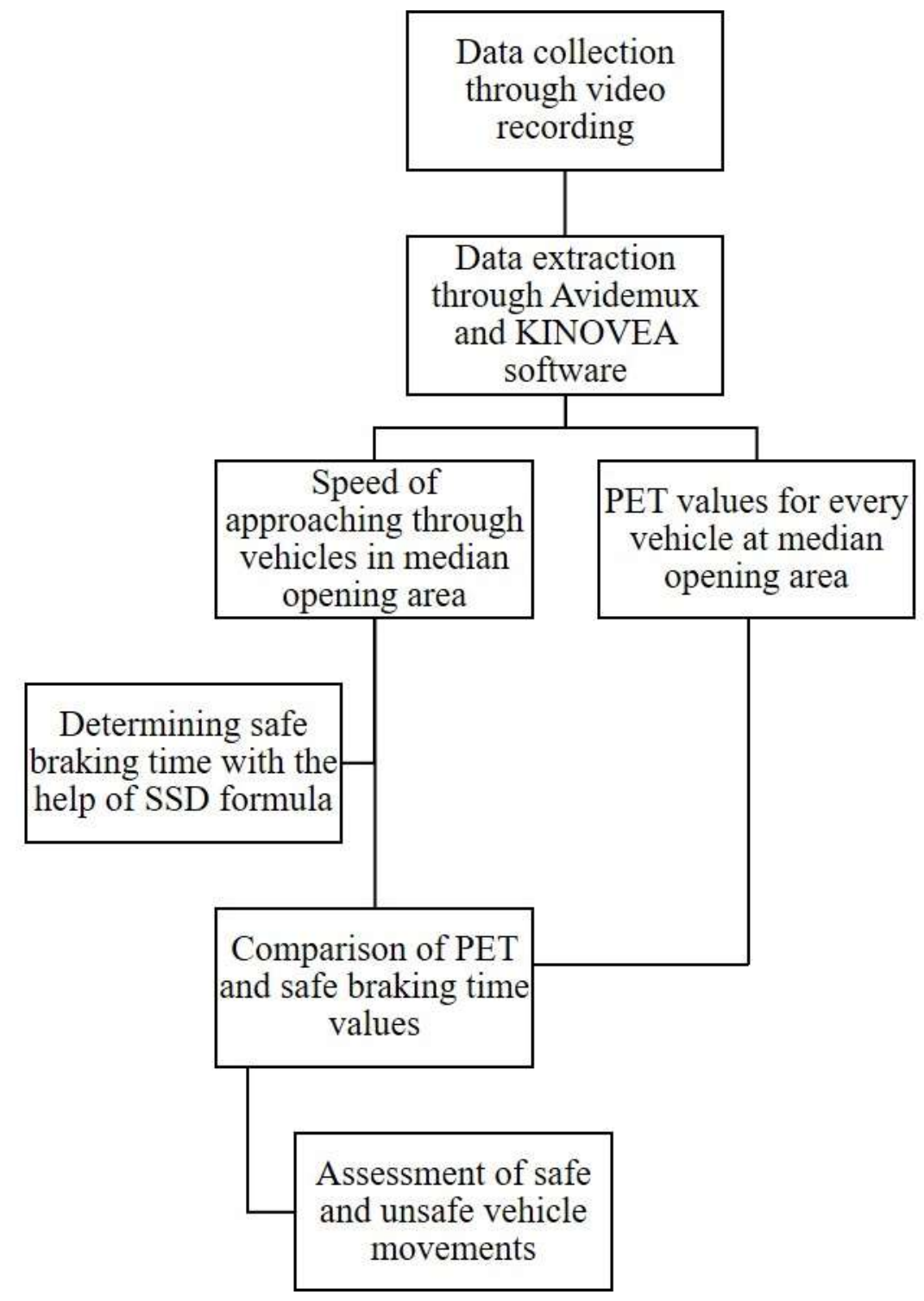

Figure 2 Flow chart for methodology 


\subsubsection{Speed of the approaching through vehicles}

The recorded videos were played on a laptop screen and TV monitor in the Kinovea software. The software has capabilities to mark lines for 2 specific distances and also provide the distances. This helped in calculation of the speeds of each vehicles. The time at which a vehicles crosses each line is noted down. The distance covered, which is a known entity is then divided by the time difference to get the speed. Figure 3 below shows a snapshot of the KINOVEA software.

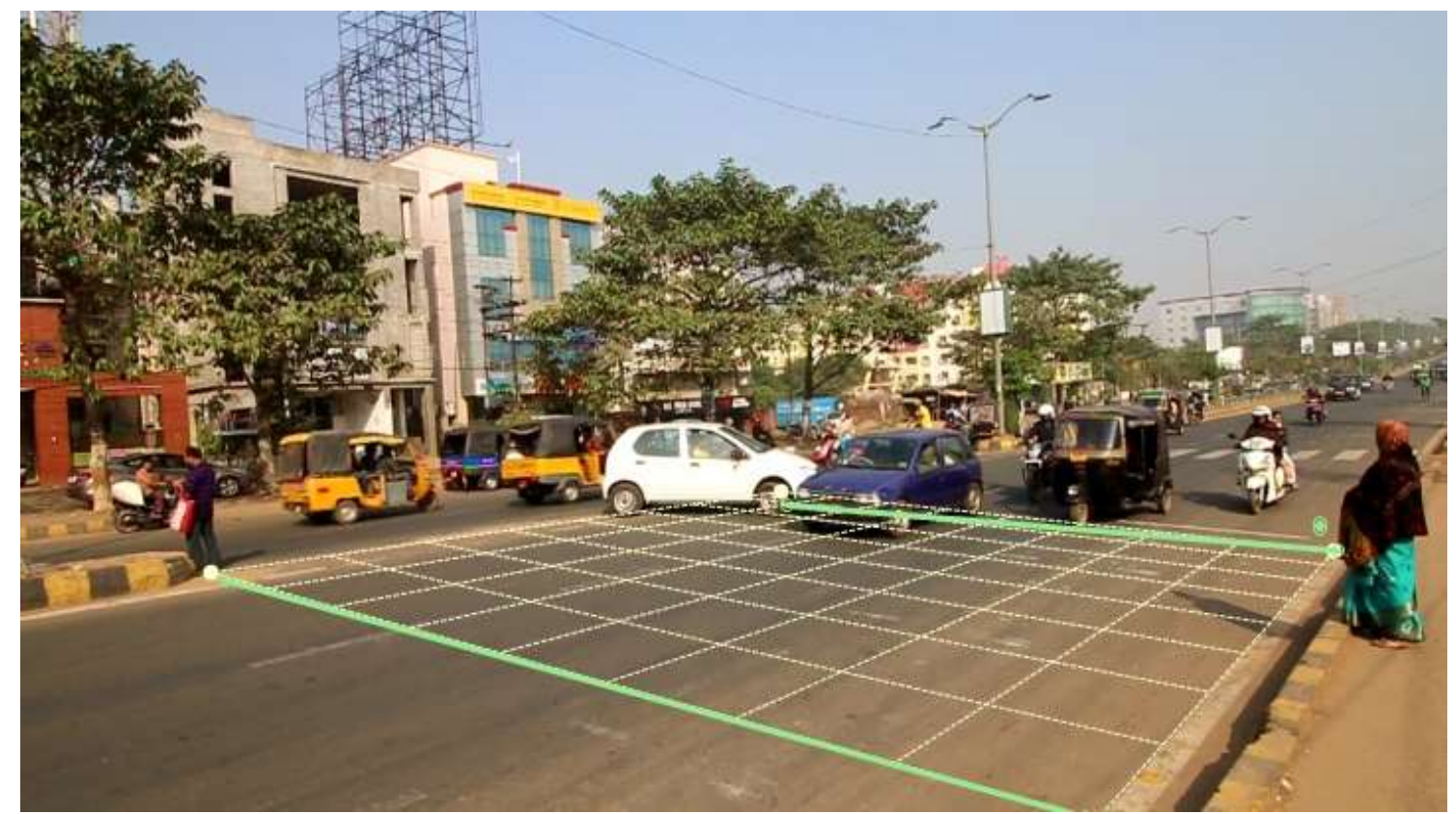

Figure 3 Snapshot of KINOVEA software for examining traffic speed

\subsubsection{Calculation of PET values}

Post Encroachment Time (PET) is one of the most frequently used method to analyze road safety of any traffic facility (Gettman and Head, 2003; Killi and Vedagiri, 2014). Post Encroachment Time (PET) is a safety indicator that represents a measure of the temporal difference between two road-users over a common spatial point or area. This should be below a predetermined maximum threshold value (Archer, 2005). The PET concept has been used as part of the Dutch and Canadian conflict techniques (Cooper, 1983; van der Horst \& Kraay 1986; Hydén, 1987; Topp 1998). In the present study, the PET has been calculated according to Figure 4 illustrated below.

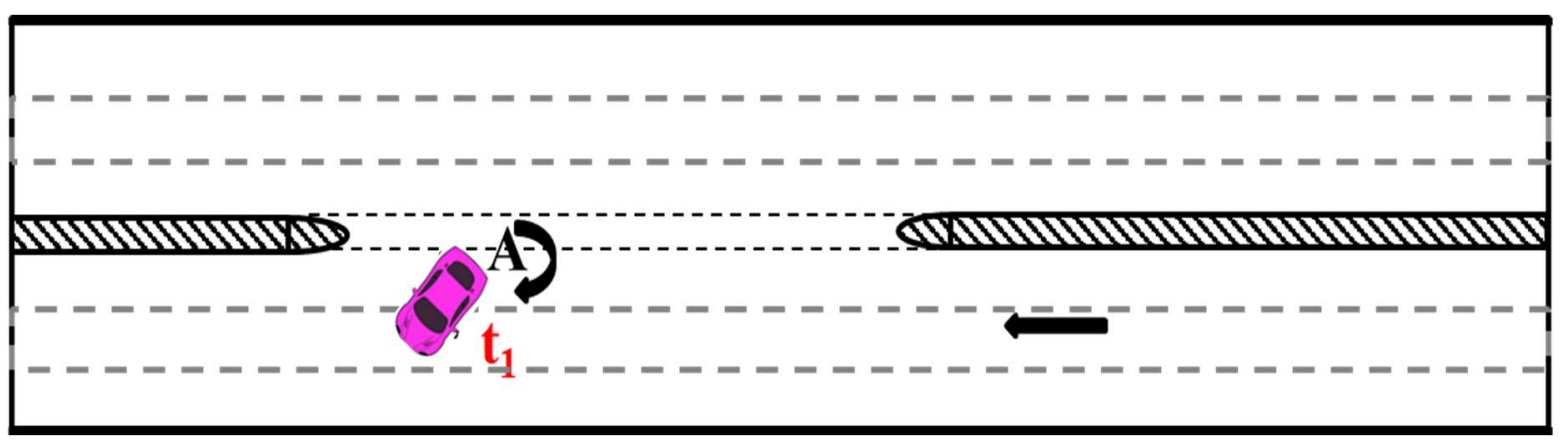




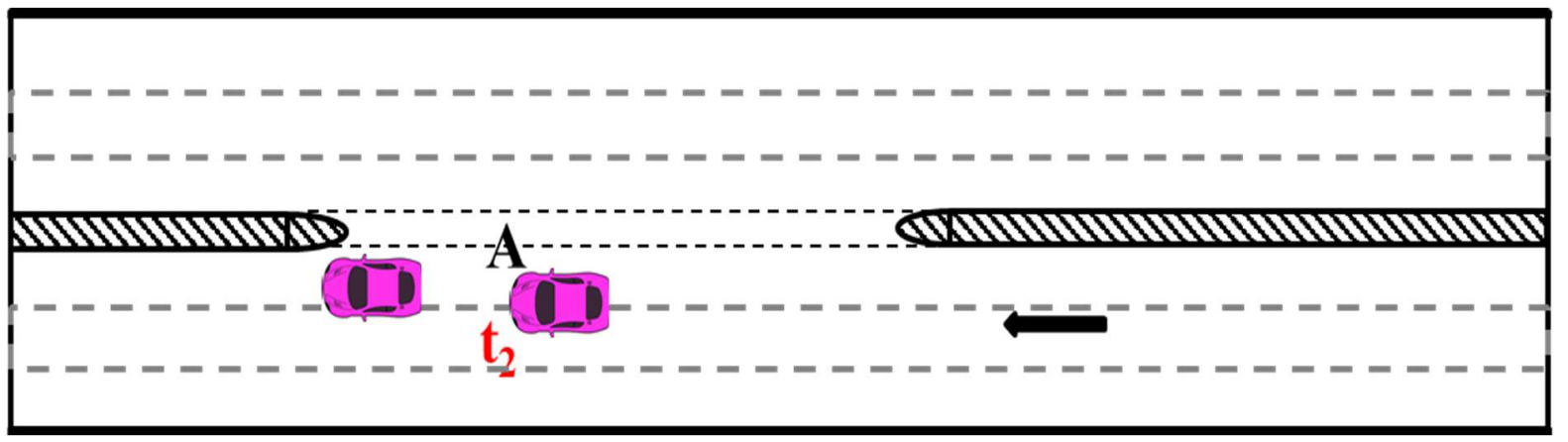

Figure 4 Calculation of PET at median openings

As shown in Figure 4, A represents the point of conflict, where if the U-turn vehicle would have stopped or the approaching through vehicle wouldn't have slowed down would have led to collision. $t_{1}$ represents the time at which the U-turn vehicle leaves the conflict point and $t_{2}$ represents the time at which approaching through vehicle reaches at the same probable conflict point. Here, PET for the vehicle is calculated as the difference between $t_{2}$ and $t_{1}$. In other words,

$$
\mathrm{PET}=\mathrm{t}_{2}-\mathrm{t}_{1}
$$

\subsubsection{Calculation of safe braking time}

The safe braking time has been calculated based on the obtained speed and using the formula for stopping sight distance (SSD). The IRC guidelines have also been used to take the values for longitudinal friction ' $\mathrm{f}$ ' during the calculation of SSD. IRC 66-1976 contains the guidelines for providing the sight distances on highways in India. Stopping sight distance is the minimum sight distance for which all roads must always be designed, regardless of any other consideration. It is the clear distance ahead needed by a driver to stop his vehicle before meeting a stationary object in his path on the road (IRC: 66-1976). The minimum stopping sight distance for any vehicle is calculated by using the following equation.

$$
\mathrm{SSD}=0.278 . \mathrm{v} \cdot \mathrm{t}+\left(\mathrm{v}^{2} / 254 . \mathrm{f}\right)
$$

Where, $\mathrm{SSD}=$ minimum stopping time distance, $\mathrm{m}$

$\mathrm{v}=$ initial speed of the vehicle, $\mathrm{km} / \mathrm{h}$

$\mathrm{t}=$ reaction time of the driver, $\mathrm{s}$

$\mathrm{f}=$ coefficient of longitudinal friction $(0.35-0.4)$

In this equation, the first part $(0.278 * \mathrm{v} * \mathrm{t})$ is called the lag distance/ the distance travelled before being able to perceive and react to the traffic condition whereas the second part $\left(\mathrm{v}^{2} / 254 * \mathrm{f}\right)$ is denoted as the braking distance/the actual distance covered while slowing the vehicle from $\mathrm{v}$ to 0 . A reaction time of $2.5 \mathrm{~s}$ is usually considered to calculate the lag distance. Table 2 below presents the values of stopping sight distance provided by the code. This must be noted that the results in Table 2 have been obtained by applying Equation 2 which is a universal formula used for calculation of SSD. 
Table 2 Safe stopping distance at differenct speeds

\begin{tabular}{ccccccc}
\hline $\begin{array}{c}\text { Speed } \\
(\mathbf{k m} / \mathbf{h})\end{array}$ & \multicolumn{2}{c}{$\begin{array}{c}\text { Perception and } \\
\text { brake reaction }\end{array}$} & \multicolumn{2}{c}{ Braking } & \multicolumn{2}{c}{$\begin{array}{c}\text { Safe stopping sight distance } \\
(\mathbf{m})\end{array}$} \\
\cline { 2 - 7 } & $\begin{array}{c}\text { Time } \\
(\mathbf{s})\end{array}$ & $\begin{array}{c}\text { Distance } \\
(\mathbf{m})\end{array}$ & $\begin{array}{c}\text { Coeff. of } \\
\text { friction }\end{array}$ & $\begin{array}{c}\text { Distance } \\
(\mathbf{m})\end{array}$ & $\begin{array}{c}\text { Calculated } \\
\text { values (m) }\end{array}$ & $\begin{array}{c}\text { Design } \\
\text { values (m) }\end{array}$ \\
\hline $\mathbf{2 0}$ & 2.5 & 14 & 0.40 & 4 & 18 & 20 \\
\hline $\mathbf{2 5}$ & 2.5 & 18 & 0.40 & 6 & 24 & 25 \\
\hline $\mathbf{3 0}$ & 2.5 & 21 & 0.40 & 9 & 30 & 30 \\
\hline $\mathbf{4 0}$ & 2.5 & 28 & 0.38 & 17 & 45 & 45 \\
\hline $\mathbf{5 0}$ & 2.5 & 35 & 0.37 & 27 & 62 & 60 \\
\hline $\mathbf{6 0}$ & 2.5 & 42 & 0.36 & 39 & 81 & 80 \\
\hline $\mathbf{6 5}$ & 2.5 & 45 & 0.36 & 46 & 91 & 90 \\
\hline $\mathbf{8 0}$ & 2.5 & 56 & 0.35 & 72 & 128 & 130 \\
\hline $\mathbf{1 0 0}$ & 2.5 & 70 & 0.35 & 112 & 182 & 180 \\
\hline
\end{tabular}

According to the table above, suppose a vehicle is travelling at a speed of $40 \mathrm{~km} / \mathrm{h}$, and it sees a vehicle or pedestrian or any object in front of it, it will travel $45 \mathrm{~m}$ before coming to halt. However, in this $45 \mathrm{~m}$ of movement, the vehicle will move $28 \mathrm{~m}$ while trying to perceive the traffic situation without actually applying its brake, and the actual braking distance is $17 \mathrm{~m}$ which is the minimum distance required by a vehicle to come to 0 from $45 \mathrm{~km} / \mathrm{h}$ after applying the brake. However, according to Mohanty \& Dey (2017) the approaching through vehicles start to slowdown at $40-50 \mathrm{~m}$ on the upstream of start of median opening which proves that while approaching towards the median opening, the vehicles have already perceived the traffic condition. Therefore, the approaching through vehicles only need to travel the braking distance to stop their vehicles within the median opening area. Therefore, Equation 2 can be written as follows without the lag distance.

$$
\mathrm{SSD}=\left(\mathrm{v}^{2} / 254 . f\right)
$$

This average approaching speed (v) obtained from data extraction is directly put in Equation 3 to calculate the braking distance. Further, from the obtained braking distance and the average speed, braking time is obtained for each traffic volume level. In order to calculate the braking time, a simple equation is used which is obtained by substitution of equations of motion. The general equations of motions are presented below as Equation 4, 5, and 6.

$$
\begin{gathered}
\mathrm{v}_{\mathrm{f}}=\mathrm{vi}_{\mathrm{i}}+\mathrm{a} . \mathrm{t} \\
\mathrm{vf}^{2}-\mathrm{vi}^{2}=2 . \mathrm{a} \cdot \mathrm{s} \\
\mathrm{s}=\mathrm{v}_{\mathrm{i}} . \mathrm{t}+0.5 \mathrm{a} . \mathrm{t}^{2}
\end{gathered}
$$

Where,

$\mathrm{v}_{\mathrm{i}}=$ Initial speed,

$\mathrm{v}_{\mathrm{f}}=$ Final speed,

$\mathrm{a}=$ Acceleration/Deceleration,

$\mathrm{s}=$ Distance covered during change of speed from $\mathrm{v}_{\mathrm{i}}$ to $\mathrm{v}_{\mathrm{f}}$,

$t=$ Time elapsed during change of speed from $v_{i}$ to $v_{f}$.

At first if we multiply ' $t$ ' on both the sides of Equation 4, we get the expression,

However, Equation 6 can be rearranged as

$$
v_{f} . t=v_{i} . t+a . t^{2}
$$




$$
\text { a.t } t^{2}=2\left(s-v_{i} \cdot t\right)
$$

Finally, applying the value of a.t ${ }^{2}$ in Equation 7, the following mathematical expression is obtained.

$$
v_{f} . t=v_{i} . t+2 . s-2 . v_{i} \cdot t
$$

Equation 9 can be rephrased as

$$
\mathrm{s}=0.5 . \mathrm{t} .\left(\mathrm{v}_{\mathrm{f}}+\mathrm{v}_{\mathrm{i}}\right)
$$

Equation 10 has been used to calculate the average braking time of approaching through vehicles at different traffic volume levels using the average speed and braking distance of approaching through vehicles.

\section{Results \& Discussions}

The present study has been divided into three sub studies as follows.

(i) Calculation of speed of approaching through vehicles within the median opening area.

(ii) Determination of safe braking time with the help of IRC guidelines and obtained speed data.

(iii) Assessing the proportion of safe and unsafe vehicles at different traffic volumes based on calculated PET values.

\subsection{Speed analysis at median opening}

Due to the limited priority situation, while approaching towards a median opening, the approaching through vehicles start decelerating in the upstream of the median opening. Therefore, a possible slowdown section exists for the vehicles approaching toward the median opening (Mohanty and Dey, 2017). Mohanty and Dey (2017) reported that the slowdown section starts at a distance of 40-50 m on the upstream of median opening. This clearly indicates that while approaching a median opening, the approaching through vehicles already perceive the traffic situation beforehand (i.e. at the start of slowdown section) and become more cautious due to the presence of U-turns. Therefore, in the present study, the speeds of all the approaching through vehicles within the median opening area (from start to end of median opening as per Fig. 1) at various traffic volume levels have been determined from the recorded field data. The average speeds of the traffic stream at different traffic volume levels have been presented in the Table 3. It is obvious that, as traffic volume increases, the average speed of traffic stream decreases. Lower the vehicle speed, less time it requires to stop by braking. Therefore, this speed of vehicles largely affects the safety and collision probability within the median opening area which shall be discussed in the next section.

Table 3 Average speed of vehicles within the median opening

\begin{tabular}{cccccc}
\hline $\begin{array}{c}\text { Traffic volume } \\
\text { levels, vph }\end{array}$ & $\mathbf{1 0 0 0 - 2 0 0 0}$ & $\begin{array}{c}\mathbf{2 0 0 0 -} \\
\mathbf{3 0 0 0}\end{array}$ & $\mathbf{3 0 0 0 - 4 0 0 0}$ & $\begin{array}{c}\mathbf{4 0 0 0 -} \\
\mathbf{5 0 0 0}\end{array}$ & $>\mathbf{5 0 0 0}$ \\
\hline $\begin{array}{c}\text { Average speed, } \\
\text { kmph }\end{array}$ & 42.5 & 33.5 & 21.0 & 18.5 & 15.5 \\
\hline
\end{tabular}




\subsection{Braking time analysis}

As per the decription in Section '2.2.3 Calculation of safe braking time' the safe braking time has been calculated using the average speeds obtained from the data as presented in Table 3. The calculated braking distances and braking time for different traffic volume levels have been presented in Table 4.

Table 4 Braking distance and braking time at different traffic volume levels

\begin{tabular}{cccccc}
\hline \multirow{2}{*}{$\begin{array}{c}\text { Average speed of } \\
\text { vehicles (km/h) }\end{array}$} & \multicolumn{5}{c}{ Approaching through traffic volume (vph) } \\
\cline { 2 - 6 } & $\mathbf{1 0 0 0 - 2 0 0 0}$ & $\mathbf{2 0 0 0 - 3 0 0 0}$ & $\mathbf{3 0 0 0 - 4 0 0 0}$ & $\mathbf{4 0 0 0 - 5 0 0 0}$ & $>\mathbf{5 0 0 0}$ \\
\hline $\begin{array}{c}\text { Braking distance } \\
\text { (m) }\end{array}$ & 17.78 & 33.5 & 21.0 & 18.5 & 15.5 \\
\hline Braking time (s) & 3.01 & 11.04 & 4.34 & 3.37 & 2.36 \\
\hline
\end{tabular}

Table 4 clearly indicates that the braking times decrease with increase in traffic volume levels. This is obvious as the average speed of approaching through vehicles decrease with increase in traffic volume levels. It can be said that at a particular traffic volume, the obtained braking time is the minimum possible time required for any vehicle to stop completely within the median opening area as Equation 2 which has been used for calculation assumes $100 \%$ braking efficiency of the vehicles.

\subsection{Proportion of safe and unsafe vehicles}

In the present study, PET values have been calculated for approaching through vehicles at different traffic volume levels. Subsequently, this PET is compared with the minimum braking time (Table 4) calculated for a particular traffic volume. If the obtained PET is less than the calculated braking time, the vehicle movement is considered to be unsafe as the time available to stop the approaching through vehicle is less than the minimum time required to stop the vehicle at that particular traffic volume. However, if obtained PET is greater than the calculated braking time, the vehicle's movement is considered to be safe as the vehicle can stop by applying brakes before colliding with the conflicting vehicle. Table 5 shows the details of calculated PETs and the percentage of vehicles safe and unsafe moving within the median opening area at every traffic volume levels.

Table 5 Percentage of safe and unsafe vehicle movement at median openings

\begin{tabular}{|c|c|c|c|c|c|c|}
\hline $\begin{array}{c}\text { Traffic } \\
\text { volume, } \\
\text { vph }\end{array}$ & $\begin{array}{c}\text { Minimum } \\
\text { PET }\end{array}$ & $\begin{array}{c}\text { Maximum } \\
\text { PET }\end{array}$ & $\begin{array}{l}\text { Mean } \\
\text { PET }\end{array}$ & $\begin{array}{l}\text { Braking } \\
\text { time } \\
\text { (Table 4) }\end{array}$ & $\begin{array}{c}\text { \% of safe } \\
\text { vehicle } \\
\text { movemen } \\
t \\
\end{array}$ & $\begin{array}{c}\text { \%o of } \\
\text { unsafe } \\
\text { vehicle } \\
\text { movement }\end{array}$ \\
\hline $\begin{array}{l}1000- \\
2000\end{array}$ & 0.12 & 2.92 & 0.89 & 3.01 & 0.00 & 100.00 \\
\hline $\begin{array}{l}\text { 2000- } \\
3000\end{array}$ & 0.36 & 2.63 & 0.92 & 2.37 & 3.22 & 96.78 \\
\hline $\begin{array}{l}3000- \\
4000\end{array}$ & 0.56 & 2.96 & 1.41 & 1.49 & 38.67 & 61.33 \\
\hline $\begin{array}{c}4000- \\
5000\end{array}$ & 0.72 & 3.40 & 1.36 & 1.31 & 44.75 & 55.25 \\
\hline$>5000$ & 0.66 & 2.88 & 1.28 & 1.10 & 42.90 & 57.10 \\
\hline
\end{tabular}


Table 5 indicates that the vehicular movements are highly unsafe at lower approaching through volumes $(<3000 \mathrm{vph})$. This is because of the high speeds of vehicles accompanied by low PET values. However, less crashes are observed at low traffic volume levels. Usually at lower traffic volumes, approaching through vehicles get lateral space to change their lanes, thereby avoiding conflict with the U-turns (Mohanty et al., 2016). Therefore, it can be concluded that even though less crashes are observed at low traffic volumes, if a crash occurs it will be severe as more than $95 \%$ of vehicular movements are unsafe. Similarly, at higher traffic volumes (>3000 vph), around 55-60 $\%$ of vehicular movements are unsafe. At higher volumes, due to more number of vehicles on road, lane changing ability of drivers reduces (Mohanty et al., 2016). Hence, drivers become cautious and move at lower speeds (Mohanty and Dey, 2018). Therefore, it is observed that around $40-45 \%$ of the vehicular movements are safe. This methodology helps to determine the amount of safe and unsafe vehicles beforehand which will better augment traffic engineers to maintain the traffic safety at median openings. Further, it should be noted that the PET values don't determine probability of crashes; rather it estimates the severity of the crashes. Therefore, though the number of crashes may be less at lower traffic volumes, but the severity of those crashes will be very high as compared to the crashes occurring at higher traffic volumes.

\section{Conclusions}

Traffic movements at median openings is highly complex and complicated. It is attributed to high speed of approaching through vehicles having a possible conflict with the U-turning vehicles who make a 180 degree maneuver to merge with the approaching through traffic stream. These complex movements at uncontrolled median openings increases the risk of collision posing a threat to the safety of both approaching through and U-turning vehicles. In the present study, a new technique is proposed to predict the severity of probable road crashes at median opening area.

At first, a speed profile study is conducted to calculate the average speed of approaching through vehicles at different traffic volume levels. It is observed that with increase in traffic volume, the average speed of approaching through vehicles decreases within the median opening area. Thereafter, utilising the obtained average speed of approaching through vehicles, the minimum braking distances and braking times for approaching through vehicles at different traffic volumes is estimated by the help of the equation generally used for calculation of stopping sight distance (SSD) along with the equations of motion. The values for ' $f$ ' i.e. longitudinal friction is taken from the Indian codes as the study has been conducted in India. Thereafter, PET values are determined for approaching through vehicles at various traffic volume levels. The obtained PET values are then compared with the respective braking times for each traffic volume level. If the PET value is found to be more than the braking time, the vehicular movement is considered to be safe. Whereas, less PET value as compared to the braking time is considered unsafe as the plying vehicle has less time to stop its vehicle as compared to the minimum required time. The results showed that more than $95 \%$ of the vehicular movements at low traffic volumes are unsafe due to high speeds of the vehicles accompanied by low PET values. However, at higher volumes, around 40-45\% of vehicular movements are considered safe. The reason is attributed to low operating speeds of vehicles at higher traffic volumes due to unavailability of space.

The present study proposes a new methodology to assess the safety of vehicular movements at the uncotnrolled median opening. The study helps in predicting the severity 
of probable road crashes beforehand. The study doesn't predict the number of road crashes; rather it predicts the severity of probable road crash (if happens) at different traffic volume levels within the median opening area. This will help in maintaining the traffic situation at median openings and take possible measures to increase the safety and decrease probable injuries among road users.

\section{References}

"Road Accidents in India - 2017", Ministry of Road Transport and Highways (2017).

"World Population Prospects: The 2017 Revision", United Nations Department of Economic and Social Affairs (2017).

Aldian, A., and M. A. Taylor. (2001). "Selecting priority junction traffic models to determine U-turn capacity at median opening." Proc. East. Asia Soc. Transp. Stud. 3 (2), 101-113.

Archer, J. (2005). "Indicators for traffic safety assessment and prediction and their application in micro-simulation modelling: A study of urban and suburban intersections", Doctoral dissertation, KTH, Sweden.

Caliendo, C., and Guida, M. (2012) "Microsimulation approach for predicting crashes at unsignalized intersections using traffic conflicts", Journal of transportation engineering, ASCE, 138(12), 1453-1467.

Cooper, P.J., (1983). "Experience with Traffic Conflicts in Canada with Emphasis on Post Encroachment Time Techniques", In International Calibration Study of Traffic Conflicts, NATA ASI Series, Vol. F5, Springer-Verlag, Heidelberg, Germany pp.7596.

Darzentas, J., Cooper, D. F., Storr, P. A., and McDowell, M. R. C. (1980). "Simulation of road traffic conflicts at T-junctions", Simulation, 34(5), 155-164.

Gettman, D., and Head, L. (2003). "Surrogate safety measures from traffic simulation models", Transportation Research Record, 1840(1), 104-115.

Hydén, C. (1987). "The Development of a Method for Traffic Safety Evaluation: The Swedish Traffic Conflicts Technique", Bulletin 70, Dept. of Traffic Planning and Engineering, Lund University, Lund, Sweden.

IRC 66-1976 "Recommended Practice for Sight Distance on Rural Highways", Indian Roads Congress.

Killi, D. V., and Vedagiri, P. (2014) "Proactive Evaluation of Traffic Safety at An Unsignalized Intersection Using Micro-Simulation", Journal of Traffic and Logistics Engineering, 2(2), 140-145.

Mohanty, M., and Dey, P. P. (2017). "Assessment of major stream delay at median openings", Transportation Letters, Taylor \& Francis, DOI: 10.1080/19427867.2017.1401701.

Mohanty, M., and Dey, P. P. (2018) "Major Stream Delay under Limited Priority Conditions", Journal of Transportation Engineering, Part A: Systems, ASCE, 145(3), 05018005.

Mohanty. M., Dey, P. P., and Ojha, A. K. (2016) "Assessment of lane changing behaviour due to U-turns using markov process", 96th Annual Meeting, Transportation Research Board, Paper no. 17-01905.

Mohapatra, S. S., Dey, P. P., and Chandra, S. (2016). "Modeling the critical position of U-turning vehicles at uncontrolled median openings", KSCE Journal of Civil Engineering, 20(1), 411-420. 
Pulugurtha, S., Ghosh, I., and Biswas, S. (2019). "Advances in Transportation Engineering", TRACE -2018, Springer.

Songchitruksa, P., and Zha, L. (2014) "Advancing Safety Performance Monitoring at Signalized Intersections Using Connected Vehicle Technology”, 93rd Annual Meeting, Transportation Research Board.

Topp, H.H. (Ed.), (1998). “Traffic Safety Work with Video-Processing”, University Kaiserslautern. Transportation Department, 1998, Green Series No.43, Kaiserslautern, Germany.

Van der Horst, R., and Kraay, J. (1986). "The Dutch Conflict Observation Technique DOCTOR", Proceedings of Workshop - Traffic Conflicts and Other Intermediate Measures in Safety Evaluation, Budapest, Hungary.

Vedagiri, P., and Pragna, T. (2013) "Evaluation of traffic safety at unsignalized intersections under mixed traffic conditions," Transportation Research Board 92nd annual meeting. 